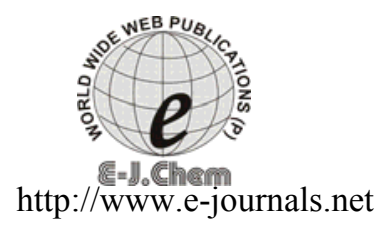

ISSN: 0973-4945; CODEN ECJHAO

E-Journal of Chemistry

2011, 8(S1), S349-S357

\title{
NO Reactions Over Ir-Based Catalysts in the Presence of $\mathrm{O}_{2}$
}

\author{
MINGXIN GUO, RONGSHU ZHU, MINHUA DONG and FENG OUYANG* \\ Environmental Science and Engineering Research Center \\ Harbin Institute of Technology Shenzhen Graduate School \\ Shenzhen 518055, China \\ ouyangfh@hit.edu.cn
}

Received 21 January 2011; Accepted 12 April 2011

\begin{abstract}
The behaviour of a series of Ir-based catalysts supported on $\mathrm{SiO}_{2}$, ZSM-5 and $\gamma-\mathrm{Al}_{2} \mathrm{O}_{3}$ with various Ir loadings prepared by impregnation method was conducted by temperature programmed reaction (TPR) technique. The result implies that $\mathrm{NO}$ is oxidized to $\mathrm{NO}_{2}$ while simultaneously being reduced to $\mathrm{N}_{2}$ or $\mathrm{N}_{2} \mathrm{O}$ in the $\mathrm{NO}$ reactions over iridium catalysts. The surface active phase over iridium catalysts that promote the $\mathrm{NO}$ reactions is $\mathrm{IrO}_{2}$. The catalytic activity increases with the increase of the Ir loading and support materials have a little effect on the catalytic activity. When the loading is less than $0.1 \%$, the catalytic activity was found to be dependent on the nature of support materials and in order: $\mathrm{Ir} / \mathrm{ZSM}-5>\mathrm{Ir} / \gamma-\mathrm{Al}_{2} \mathrm{O}_{3}>\mathrm{Ir} / \mathrm{SiO}_{2}$. When the loading is higher than $0.1 \%$, the catalytic activity for $\mathrm{NO}$ oxidation is in order: Ir/ZSM$5>\mathrm{Ir} / \mathrm{SiO}_{2}>\mathrm{Ir} / \gamma-\mathrm{Al}_{2} \mathrm{O}_{3}$, which is correlated with Ir dispersion on the surface of support materials and the catalytic activity for $\mathrm{NO}$ reduction is in sequence: $\mathrm{Ir} / \gamma-\mathrm{Al}_{2} \mathrm{O}_{3}>\mathrm{Ir} / \mathrm{SiO}_{2}>\mathrm{Ir} / \mathrm{ZSM}-5$, which is attributed to the adsorbed-dissociation of $\mathrm{NO}_{2}$. Compared to $\mathrm{Pt} / \gamma-\mathrm{Al}_{2} \mathrm{O}_{3}, \mathrm{Ir} / \gamma-\mathrm{Al}_{2} \mathrm{O}_{3}$ catalyst is more benefit for the $\mathrm{NO}$ reduction.
\end{abstract}

Keywords: Ir, NO oxidation, NO reduction, $\mathrm{Pt}$

\section{Introduction}

With the increase concerns about energy crisis and global warming, more severe requirements about the emission of greenhouse gas $\mathrm{CO}_{2}$ and conservation of energy have been progressively brought forward. In this context, particular concern has been addressed to the lean burn which can greatly reduce the $\mathrm{CO}$ and hydrocarbon as well as improve utilization and economy of fuel. In addition, the automotive industry is currently facing serious challenges to meet the specific requirements of future regulations concerning NOx. However, the conventional three-way catalysts are not effective for NOx reduction due to 
the preferential oxidation of reductants with excess oxygen under lean burn condition. Hence, the catalytic removal of NOx under excess oxygen conditions is an issue full of challenges in catalytic science.

In the past years, several technologies have been developed in order to catalytic removal of NOx under rich-oxygen environment including the catalytic decomposition, selective catalytic reduction, storage and catalytic reduction. Among these catalytic systems, noble metal catalysts have drawn many researchers' eyes owing to their high activity at low temperature and the strong resistance to poisoning by $\mathrm{SO}_{2}$ and $\mathrm{H}_{2} \mathrm{O}^{1-15}$. Now, more and more attentions have been put on the activity of iridium catalysts ${ }^{5-10}$.

Ir-based catalysts show high catalytic activity and $\mathrm{N}_{2}$ selectivity when NO reduced with hydrocarbon in rich-oxygen environment. Among $\mathrm{Pt}, \mathrm{Pd}, \mathrm{Rh}$ and $\mathrm{Ir}$ investigated in the reduction of $\mathrm{NO}$ by $\mathrm{CO}$ under excess oxygen, Ir-based catalysts show the highest catalytic activities ${ }^{7-10}$ and the presence of $\mathrm{SO}_{2}$ can promote NO reduction ${ }^{9-10}$. However, few researches has been reported for the direct catalytic reaction of $\mathrm{NO}$ over Ir-based catalysts in the presence of $\mathrm{O}_{2}$. In this work, we investigated the NO reactions over Ir-based catalysts in the presence of $\mathrm{O}_{2}$ and discussed the effect of Ir loading and support material on the NO reactions.

\section{Experimental}

The catalysts were prepared by iso-volumetric impregnation with aqueous solutions of $\mathrm{H}_{2} \mathrm{IrCl}_{6} \cdot 6 \mathrm{H}_{2} \mathrm{O}$ (Shanghai Jiuyue Chemical Co., Ltd, ) and the $\mathrm{Ir}$ content is $0.02 \mathrm{wt} . \%$, $0.1 \mathrm{wt} . \%, 1 \mathrm{wt} . \%$ and $5 \mathrm{wt} . \%$. The support materials used are ZSM-5 (Nakai University, $\mathrm{Si} / \mathrm{Al}=50$ ), active $\gamma-\mathrm{Al}_{2} \mathrm{O}_{3}$ (Dalian Luming Nanometer Material Co., Ltd, 200 500 nm, $160 \mathrm{~m}^{2} / \mathrm{g}$ ) and $\mathrm{SiO}_{2}$ (Qingdao Haiyang Chemical Co., Ltd, $0.125 \sim 0.425 \mathrm{~mm}, 460 \mathrm{~m}^{2} / \mathrm{g}$ ). All the materials were dried at $110{ }^{\circ} \mathrm{C}$ for $12 \mathrm{~h}$ after left one day at room temperature and finally calcined at $500{ }^{\circ} \mathrm{C}$ for $3 \mathrm{~h}$ in air. The powder catalysts were pressed into pellets at $10 \mathrm{Mpa}$, crushed and sieved to obtain granules of $0.250-0.425 \mathrm{~mm}$ for catalytic activity measurement. For comparison, $5 \% \mathrm{Pt} / \gamma-\mathrm{Al}_{2} \mathrm{O}_{3}$ was prepared by the iso-volumetric impregnation of $\gamma-\mathrm{Al}_{2} \mathrm{O}_{3}$ with an aqueous solution of $\mathrm{H}_{2} \mathrm{PtCl}_{6} \cdot 6 \mathrm{H}_{2} \mathrm{O}$ (Shanghai Jiuyue Chemical Co., Ltd,).

Phase identification of fresh catalysts was analyzed by XRD analyzer. The structure of iridium and platinum were measured using TEM (JEOL, JEM-2010) at an acceleration voltage of $200 \mathrm{keV}$. The iridium dispersions were measured using a Pulse chemisorb apparatus by means of hydrogen chemisorption, assuming the ratio of surface Ir to the adsorbed hydrogen atom of 1 to 1 . In order to get reproducible iridium dispersion values, several cycles of hydrogen titration were applied prior to the determination of the amount of hydrogen being chemically adsorbed on the iridium of the catalysts.

\section{Catalytic activity measurements}

In a fixed-bed continuous flow reactor, catalytic activity was evaluated by temperature programmed reaction (TPR) technique. The catalyst granules $(0.05 \mathrm{~g})$ were carefully fixed in a tubular quartz reactor (6 mm i.d.). The reaction gas which contains $\mathrm{NO}(420 \mathrm{ppm})$ and $\mathrm{O}_{2}$ (4.4vol. \%) with $\mathrm{He}$ as the balance gas was fed through the catalyst bed at a flow rate of $100 \mathrm{~mL} / \mathrm{min}$. The reaction temperature was monitored by thermocouple directly inserted into the region of the catalyst bed and controlled by a PID-regulation system (Bachy, CKW-2200). The reaction temperature was raised at a rate of $4{ }^{\circ} \mathrm{C} / \mathrm{min}$ from $100{ }^{\circ} \mathrm{C}$ to $750{ }^{\circ} \mathrm{C}$. The concentrations of $\mathrm{NO}, \mathrm{NO}_{2}$ and $\mathrm{NOx}\left(=\mathrm{NO}+\mathrm{NO}_{2}\right)$ were continuously detected by Nitrogen Oxides Analyzer (Australian Ecotech, EC-9841B). 
In order to evaluate the catalytic performance in the NO catalytic reaction, the maximal conversion ratio and the corresponding conversion temperature during the NO oxidation and $\mathrm{NO}$ reduction are adopted. In the $\mathrm{NO}$ oxidation, they are the maximal oxidation conversion ratio $\left(\eta_{o}\right)$ estimated by the ratio of $\mathrm{NO}_{2}$ formation to $\mathrm{NO}$ in the reaction gas $(420 \mathrm{ppm})$ together with the corresponding temperature named as $T_{O}$. In the NO reduction, the maximal reduction conversion ratio $\left(\eta_{R}\right)$ obtained by the ratio of the maximal NOx concentration reduced to NO in the reaction gas with the corresponding temperature named as $T_{R}$ are adopted.

Temperature programmed desorption (TPD) was done after TPR experiment. Temperature need to be cooled to room temperature in the same gas stream as TPR system and the catalyst bed was then purged in He for about $1 \mathrm{~h}$. When the signal of $\mathrm{NO}$ and $\mathrm{NO}_{2}$ from the detector had dropped to zero, TPD experiment was started in He stream with same flow rate and heating rate as that in the activity experiments.

\section{Results and discussion}

\section{Characterizations of catalysts}

Figure 1 shows the XRD results of Ir-based catalysts supported on $\gamma-\mathrm{Al}_{2} \mathrm{O}_{3}$ with different loadings. From the XRD patterns, there are no differences among $0.02 \mathrm{wt} . \%, 0.1 \mathrm{wt} . \%$ and blank $\gamma-\mathrm{Al}_{2} \mathrm{O}_{3}$, and the diffraction peaks of iridium are absent. The weak peaks of $\mathrm{IrO}_{2}$ are observed when the loading is $1 \mathrm{wt} . \%$ and the peaks of $\mathrm{IrO}_{2}$ strengthen as the loading increases to the $5 \mathrm{wt} . \%$. Hence, $\mathrm{IrO}_{2}$ is the active phase, which is consistent with the crystal phase of catalysts unreduced by $\mathrm{H}_{2}$ and the absence of $\mathrm{IrO}_{2}$ peaks with low contents reveals the high dispersive state of $\mathrm{IrO}_{2}$.

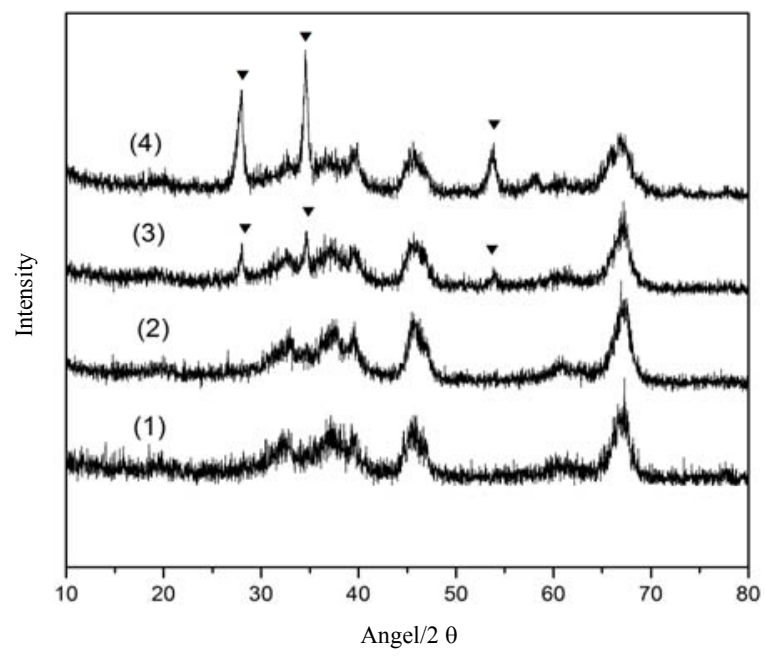

Figure 1. XRD patterns of $\mathrm{Ir} / \gamma-\mathrm{Al}_{2} \mathrm{O}_{3}$ with different Ir contents: (1) zero, (2)0.1wt.\%, (3) 1 wt. $\%$ and (4) 5wt.\%. $\mathrm{IrO}_{2}$

Figure 2 shows TEM images of 1wt.\% Ir over different supports. From it, we can find that Ir particles are well dispersed over the surface of ZSM-5 and accumulative over the surface of $\gamma-\mathrm{Al}_{2} \mathrm{O}_{3}$.

Table 1 gives the hydrogen chemisorption over $1 \mathrm{wt} . \% \mathrm{Ir} / \mathrm{SiO}_{2}$ and $5 \mathrm{wt} . \% \mathrm{Ir}$ supported on $\mathrm{SiO}_{2}, \gamma-\mathrm{Al}_{2} \mathrm{O}_{3}$ and ZSM-5. $\mathrm{H}_{2}$ chemisorption is corresponding to the number of $\mathrm{Ir}$ atoms 
exposed on the surface per gram of catalysts. From Table 1, with the increase of Ir content, the number of Ir atoms exposed on the surface becomes larger and there are more Ir atoms exposed on the surface over Ir/ZSM-5 with the same content.
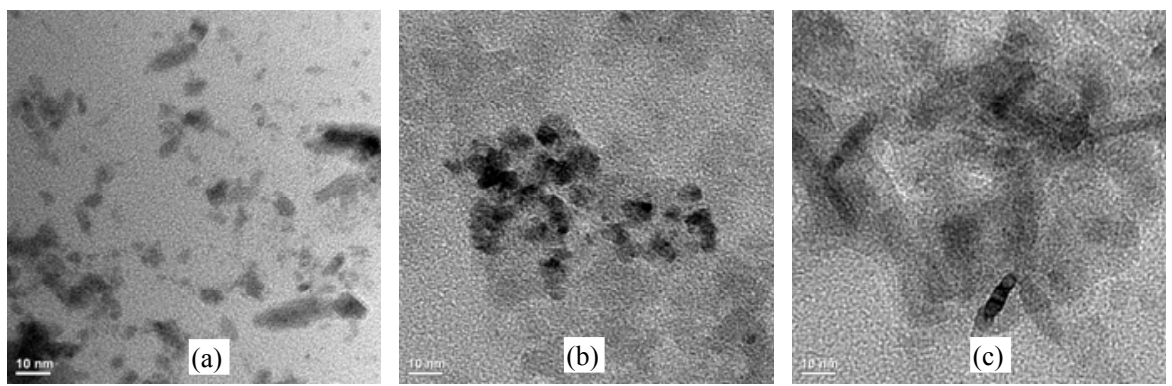

Figure 2. TEM images of $1 \mathrm{wt}$ \% Ir over (a) ZSM-5, (b) $\mathrm{SiO}_{2}$, (c) $\gamma-\mathrm{Al}_{2} \mathrm{O}_{3}$.

Table 1. Ir dispersion over catalysts

\begin{tabular}{ccccc}
\hline Catalyst & $1 \% \mathrm{Ir} / \mathrm{SiO}_{2}$ & $5 \% \mathrm{Ir} / \mathrm{SiO}_{2}$ & $5 \% \mathrm{Ir} / \gamma-\mathrm{Al}_{2} \mathrm{O}_{3}$ & $5 \% \mathrm{Ir} / \mathrm{ZSM}-5$ \\
\hline $\begin{array}{c}\text { Amount of } \mathrm{H}_{2} \\
\begin{array}{c}\text { adsorption, } \\
\mu \mathrm{mol} \cdot \mathrm{g}_{\text {cat }}^{-1}\end{array}\end{array}$ & 19.4 & 101.95 & 29.66 & 111.42 \\
\hline
\end{tabular}

\section{Reactions of NO over Ir/ZSM-5}

Figure 3 shows the TPR results of NO reaction over Ir/ZSM-5. From Figure 3(a), we can find that the concentration of $\mathrm{NO}_{2}$ begins to increase at $300{ }^{\circ} \mathrm{C}$ while $\mathrm{NO}$ decrease simultaneously over $0.1 \mathrm{wt} . \% \mathrm{Ir} / \mathrm{ZSM}-5$, implying that only part of $\mathrm{NO}$ is oxidized to $\mathrm{NO}_{2}$ (equation (1)). The concentration of $\mathrm{NO}_{2}$ reaches the maximum at $390{ }^{\circ} \mathrm{C}$ and then decreases as the temperature increases limited by the thermodynamic equilibrium among $\mathrm{NO}, \mathrm{NO}_{2}$ and $\mathrm{O}_{2}{ }^{16}$. In Figure $3(\mathrm{~b})$, the concentration of $\mathrm{NOx}\left(=\mathrm{NO}+\mathrm{NO}_{2}\right)$ over $0.1 \mathrm{wt} . \%$ Ir/ZSM-5 decreases from $300{ }^{\circ} \mathrm{C}$, reaches the lowest at $390{ }^{\circ} \mathrm{C}$ and then increases as the temperature continue to increase. From Figure 3, it is obvious that the NOx reduction is related to the oxidation of $\mathrm{NO}$ to $\mathrm{NO}_{2}$ over $0.1 \mathrm{wt} . \% \mathrm{Ir} / \mathrm{ZSM}-5$. Wang et al. ${ }^{8}$ gave a research on TPD of NO after co-adsorption with $\mathrm{O}_{2}$ over $0.1 \mathrm{wt} . \%$ Ir/ZSM-5 using GC-MS technique and found that peaks of $\mathrm{N}_{2}$ and $\mathrm{N}_{2} \mathrm{O}$ formed around $395{ }^{\circ} \mathrm{C}$. Apparently, the temperature at which NOx reaches the lowest concentration in our experiment is consistent with that of $\mathrm{N}_{2}$ and $\mathrm{N}_{2} \mathrm{O}$ formed in Wang's report ${ }^{8}$, which implied that the NOx reduced over Ir/ZSM-5 was transformed into $\mathrm{N}_{2}$ and $\mathrm{N}_{2} \mathrm{O}$. Since the reduction of $\mathrm{NOx}$ associates with $\mathrm{NO}_{2}$ formation, it can be attributed to $\mathrm{NO}_{2}$ adsorbed-decomposed to adsorbable $\mathrm{NO}(\mathrm{NO}(\mathrm{ad}))^{15,17}$ and then decompose to $\mathrm{N}_{2}\left(\mathrm{~N}_{2} \mathrm{O}\right.$ ) (equation (2)-(3)). Thus, not only the oxidation of $\mathrm{NO}$ to $\mathrm{NO}_{2}$ occurred over Ir-based catalysts, but also the reduction of $\mathrm{NO}_{2}$ adsorbed-dissociation to $\mathrm{N}_{2}$ (or $\mathrm{N}_{2} \mathrm{O}$ ) took place, simultaneously.

\section{Catalytic activity}

Figure 3, Figure 4 and Figure 5 are TPR profiles of $\mathrm{NO}, \mathrm{NO}_{2}$ and NOx over Ir/ZSM-5, $\mathrm{Ir} / \mathrm{SiO}_{2}$ and $\mathrm{Ir} / \gamma-\mathrm{Al}_{2} \mathrm{O}_{3}$ respectively and the evaluation parameters are tabulated in Table 2 . Compared with Ir-based catalysts, blank supports show negligible activity. Over the same support materials, with increase of Ir content, the oxidation activity together with the reduction activity of NO both increase. With the same Ir content, Ir/ZSM-5 is more beneficial 
for the NO oxidation but $\operatorname{Ir} / \gamma-\mathrm{Al}_{2} \mathrm{O}_{3}$ is more conducive to NO reduction. Therefore, Ir-based catalysts play an important role in the NO reaction and the loading of Ir and support materials are of important effect on the activities of Ir-based catalysts.

$$
\begin{aligned}
& \mathrm{NO}+\mathrm{O}_{2} \rightarrow \mathrm{NO}_{2} \\
& \mathrm{NO}_{2} \rightarrow \mathrm{NO}(\mathrm{ad})+\mathrm{O}(\mathrm{ad}) \\
& \mathrm{NO}(\mathrm{ad}) \rightarrow \mathrm{N}_{2}\left(\mathrm{orN}_{2} \mathrm{O}\right)+\mathrm{O}_{2}
\end{aligned}
$$
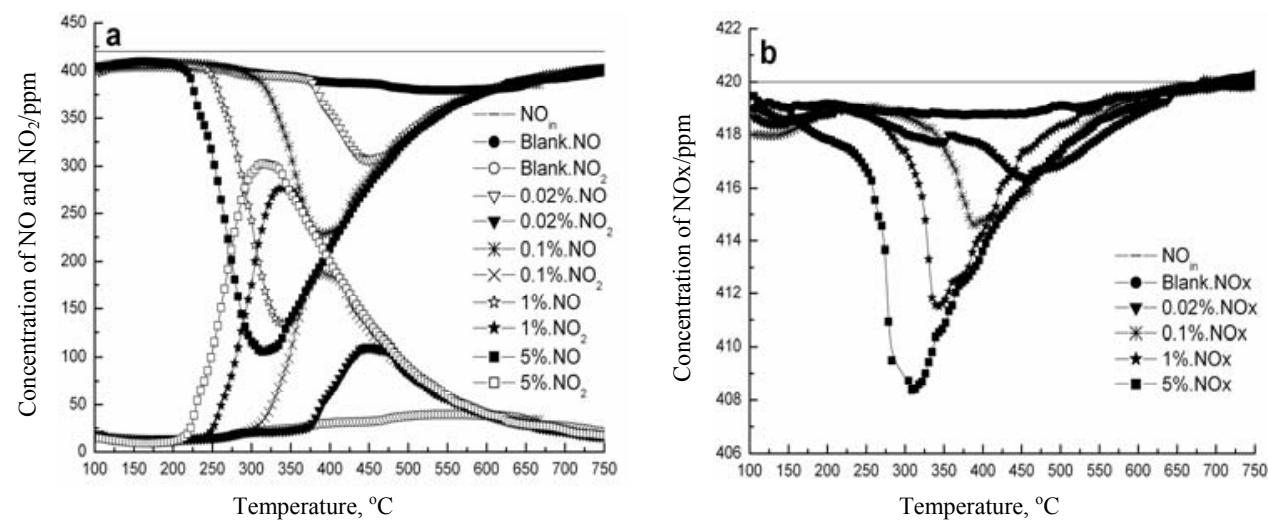

Figure 3. TPR profiles of $\mathrm{NO}, \mathrm{NO}_{2}$ and $\mathrm{NOx}$ over Ir/ZSM-5
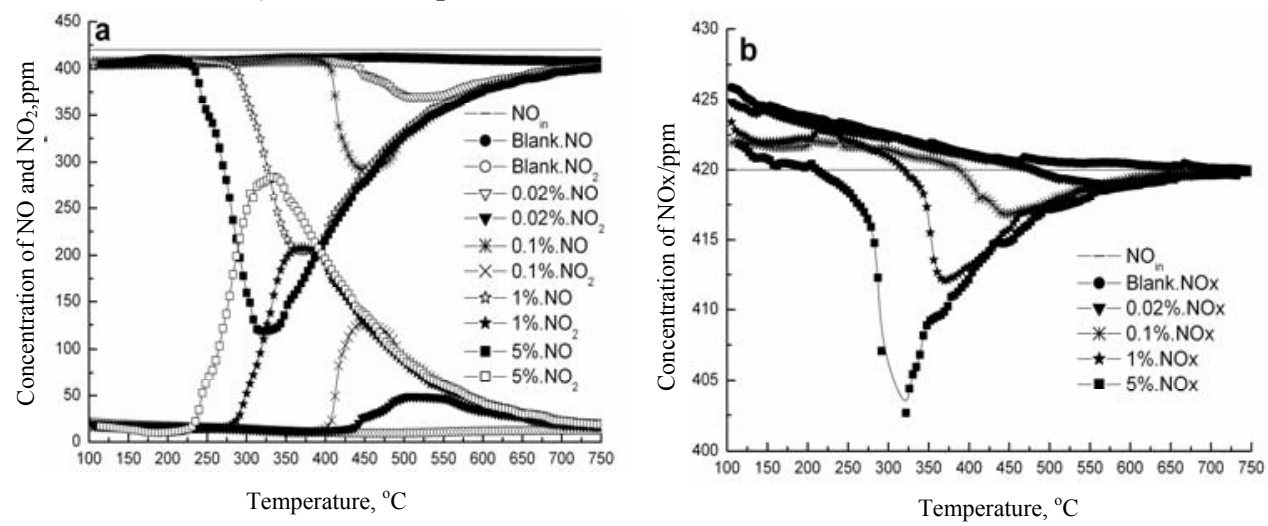

Figure 4. TPR profiles of $\mathrm{NO}, \mathrm{NO}_{2}$ and $\mathrm{NOx}$ over $\mathrm{Ir} / \mathrm{SiO}_{2}$

\section{Effect of Ir contents}

Figure 4 shows the profiles of $\mathrm{NO}$ reaction over $\mathrm{Ir} / \mathrm{SiO}_{2}$. In Figure 4(a), with the increase of Ir content, the oxidation window of NO becomes broad at low temperature, $\eta_{o}$ increases and $T_{\mathrm{O}}$ moves toward low temperature. These results show that more NO oxidized to $\mathrm{NO}_{2}$ as the content of Ir increases. Our result is similar to Xue's report ${ }^{13}$ that the oxidation activities of $\mathrm{NO}$ were observed to increase as the Pt loading increased. And this can be verified by hydrogen chemisorption over $\mathrm{Ir} / \mathrm{SiO}_{2}$ with $1 \mathrm{wt} . \%$ and $5 \mathrm{wt} . \%$ in Table 1 . With the increase of Ir content, Ir atoms exposed on the surface increase and contribute to the oxidation of NO. In Figure 4 (b), with the increase of Ir contents, the reduction window of NO becomes broad at low temperature, $\eta_{R}$ increases and $T_{R}$ moves toward low temperature. These results indicate that a higher content of Ir metal is more beneficial for the 
reduction of $\mathrm{NO}$ due to more formation of $\mathrm{NO}_{2}$ and the proceeding of equation (2) and equation (3). $T_{O}$ and $T_{R}$ were same and this further demonstrated the association between NOx reduction and $\mathrm{NO}_{2}$ production. Hence, Ir content exhibits large effect on the NO reaction over $\mathrm{Ir} / \mathrm{SiO}_{2}$ and the activities of oxidation and reduction both improve with $\mathrm{Ir}$ content increase.

From Figure 3 and Figure 5, with increase of Ir content, the oxidation activity together with the reduction activity of NO both increase over $\operatorname{Ir} / Z \mathrm{ZSM}-5$ and $\operatorname{Ir} / \gamma-\mathrm{Al}_{2} \mathrm{O}_{3}$ and these are similar to that of $\mathrm{Ir} / \mathrm{SiO}_{2}$. Compared with NO reactions over Ir supported on ZSM-5 and $\mathrm{SiO}_{2}$, an obvious discrepancy over $\mathrm{Ir} / \gamma-\mathrm{Al}_{2} \mathrm{O}_{3}$ is the strong desorption of $\mathrm{NO}$ and $\mathrm{NO}_{2}$ ranging from $100{ }^{\circ} \mathrm{C}$ to $250{ }^{\circ} \mathrm{C}$. The desorption is due to the adsorption at low temperature and this coincides with Xue et al. ${ }^{13}$
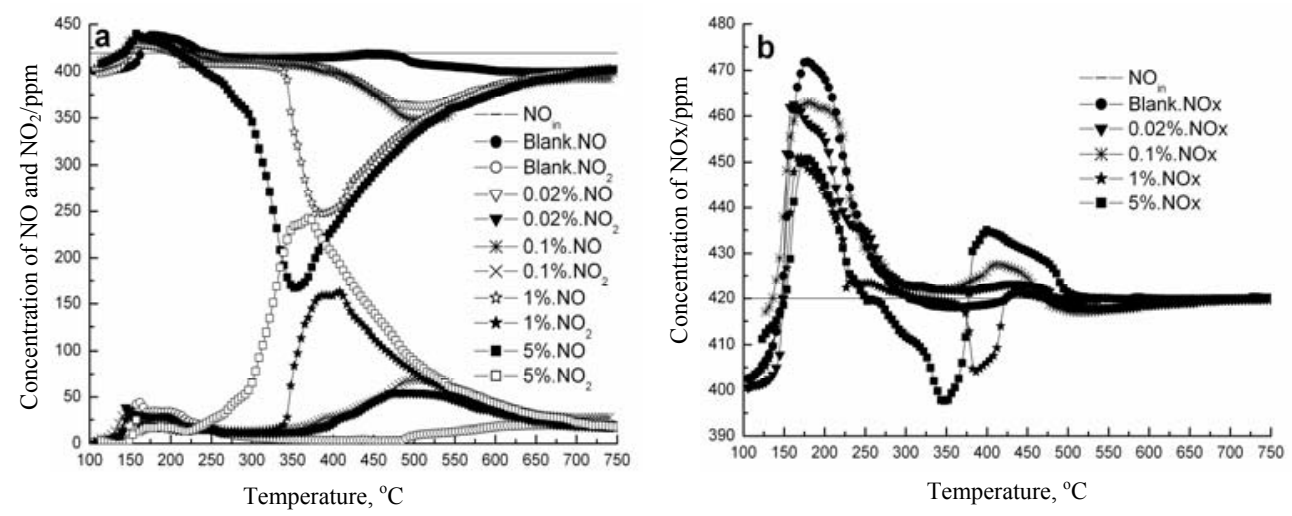

Figure 5. TPR profiles of $\mathrm{NO}, \mathrm{NO}_{2}$ and $\mathrm{NOx}$ over $\mathrm{Ir} / \gamma-\mathrm{Al}_{2} \mathrm{O}_{3}$

\section{Effect of the support materials}

In Table 2, the activity of NO oxidation over blank supports is in order: ZSM-5 $>\gamma-\mathrm{Al}_{2} \mathrm{O}_{3}>$ $\mathrm{SiO}_{2}$ and the reduction activities of $\mathrm{NO}$ are zero. This result indicates that support materials exhibited a little effect on the NO oxidation and no effect on the NO reduction. Our result about the NO oxidation is same as Xue et $a l^{13}$ report that NO oxidation primarily depends on the nature of support materials.

From the data in Table 2, we can find that the activity is in sequence: Ir/ZSM-5 > $\mathrm{Ir} / \mathrm{SiO}_{2}>\mathrm{Ir} / \gamma-\mathrm{Al}_{2} \mathrm{O}_{3}$ for catalytic oxidation of $\mathrm{NO}$ with the Ir content of $1 \mathrm{wt} . \%$. Xue et al. ${ }^{13}$ gave a research on effect of the support materials on the oxidation of $\mathrm{NO}$ to $\mathrm{NO}_{2}$ over Pt-based catalysts and found that the catalytic activity of $\mathrm{Pt} / \mathrm{SiO}_{2}$ is higher than $\mathrm{Pt} / \gamma-\mathrm{Al}_{2} \mathrm{O}_{3}$, which is similar to our result. However, these results about NO oxidation over Ir-based catalysts with the content of $1 \mathrm{wt} . \%$ were different from those obtained from blank support in the NO reactions, which gave a hint that difference in catalytic activities should be derived from discrepancy of Ir dispersion on the support surface ${ }^{18}$. Figure 2 shows the TEM images of Ir-based catalysts supported by ZSM-5, $\mathrm{SiO}_{2}$ and $\gamma-\mathrm{Al}_{2} \mathrm{O}_{3}$ with the loading of $1 \mathrm{wt} . \%$. From Figure 2, it is obviously that Ir particles are well dispersed over the surface of ZSM-5 and accumulative over the surface of $\gamma-\mathrm{Al}_{2} \mathrm{O}_{3}$. Table 1 gives the hydrogen chemisorption over 1 wt. $\%$ Ir $/ \mathrm{SiO}_{2}$ and $5 \mathrm{wt} . \%$ Ir supported on $\mathrm{SiO}_{2}, \gamma-\mathrm{Al}_{2} \mathrm{O}_{3}$ and $\mathrm{ZSM}-5$. From the data in Table 1, it is also confirmed Ir particles are well dispersed over the surface of ZSM-5 and accumulative over the surface of $\gamma-\mathrm{Al}_{2} \mathrm{O}_{3}$. From above results, $\mathrm{Ir}$ particles 
accumulated were not conducive to the catalytic oxidation of $\mathrm{NO}$ to $\mathrm{NO}_{2}$. From the comparison of catalytic reduction activities with $1 \mathrm{wt} . \%$ loading, it was found that $\eta_{R}$ is in order: $\mathrm{Ir} / \gamma-\mathrm{Al}_{2} \mathrm{O}_{3}>\mathrm{Ir} / \mathrm{SiO}_{2}>\mathrm{Ir} / \mathrm{ZSM}-5$ and the $T_{R}$ is $\mathrm{Ir} / \mathrm{ZSM}-5>\mathrm{Ir} / \mathrm{SiO} \mathrm{S}_{2}>\mathrm{Ir} / \gamma-\mathrm{Al}_{2} \mathrm{O}_{3}$. Obviously, the order of $T_{\mathrm{R}}$ is consistent with that of $T_{o}$ and the order of $\eta_{R}$ is reverse with that of $\eta_{o}$. The consistence of $T_{R}$ and $T_{O}$, was attributed to the NOx reduction closely related with $\mathrm{NO}_{2}$ formation. The contrary of $\eta_{R}$ and $\eta_{O}$ indicated that the $\mathrm{NO}$ reduction was related with $\mathrm{NO}_{2}$ formation as well as its adsorption and dissociation. Figure 6 shows TPD profile of NO after co-adsorption over $\mathrm{Ir} / \mathrm{ZSM}-5, \mathrm{Ir} / \mathrm{SiO}_{2}$ and $\mathrm{Ir} / \gamma-\mathrm{Al}_{2} \mathrm{O}_{3}$ with the content of $1 \mathrm{wt} . \%$. From figure 6 , it can be obtained that the adsorption activity is $\mathrm{Ir} / \gamma-\mathrm{Al}_{2} \mathrm{O}_{3}>\mathrm{Ir} / \mathrm{SiO}_{2}>\mathrm{Ir} / \mathrm{ZSM}-5$, which is consist with $\eta_{R}$. These implied the adsorption-dissociation of $\mathrm{NO}_{2}$ on support played an important role in NO reduction.

Table 2. Activity of catalysts for $\mathrm{NO}$ reaction

\begin{tabular}{lcccc}
\hline \multicolumn{1}{c}{ Catalyst } & $\eta_{0} \%$ & $\mathrm{~T}_{\mathrm{o}}{ }^{\circ} \mathrm{C}$ & $\eta_{R}, \%$ & $T_{R}{ }_{\mathrm{o}} \mathrm{C}$ \\
\hline $\mathrm{Blank} \mathrm{SiO}_{2}$ & 0 & & 0 & \\
$0.02 \% \mathrm{Ir} / \mathrm{SiO}_{2}$ & 11.7 & 512 & a little & \\
$0.1 \% \mathrm{Ir} / \mathrm{SiO}_{2}$ & 30.0 & 446 & 1.2 & 446 \\
$1 \% \mathrm{Ir} / \mathrm{SiO}_{2}$ & 49.5 & 369 & 2.1 & 369 \\
$5 \% \mathrm{Ir} / \mathrm{SiO}_{2}$ & 67.5 & 321 & 4.1 & 321 \\
$\mathrm{Blank} \gamma-\mathrm{Al}_{2} \mathrm{O}_{3}$ & 4.8 & $>600$ & 0 & \\
$0.02 \% \mathrm{Ir} / \gamma-\mathrm{Al}_{2} \mathrm{O}_{3}$ & 13.0 & 507 & a little & \\
$0.1 \% \mathrm{Ir} / \gamma-\mathrm{Al}_{2} \mathrm{O}_{3}$ & 16.5 & 500 & 1.5 & 500 \\
$1 \% \mathrm{Ir} / \gamma-\mathrm{Al}_{2} \mathrm{O}_{3}$ & 38.8 & 386 & 3.8 & 386 \\
$5 \% \mathrm{Ir} / \gamma-\mathrm{Al}_{2} \mathrm{O}_{3}$ & 57.7 & 352 & 5.3 & 352 \\
$\mathrm{Blank} \mathrm{ZSM}-5$ & 9.4 & $>550$ & 0 & \\
$0.02 \% \mathrm{Ir} / \mathrm{ZSM}-5$ & 26.1 & 451 & a little & 451 \\
$0.1 \% \mathrm{Ir} / \mathrm{ZSM}-5$ & 44.7 & 391 & 1.0 & 391 \\
$1 \% \mathrm{Ir} / \mathrm{ZSM}-5$ & 65.9 & 339 & 2.0 & 339 \\
$5 \% \mathrm{Ir} / \mathrm{ZSM}-5$ & 72.1 & 313 & 2.8 & 313 \\
$5 \% \mathrm{Pt} / \gamma-\mathrm{Al}_{2} \mathrm{O}_{3}$ & 58.8 & 361 & a little & \\
\hline
\end{tabular}

Catalyst weight $=0.05 \mathrm{~g}$, flow rate: $100 \mathrm{~mL} / \mathrm{min}$

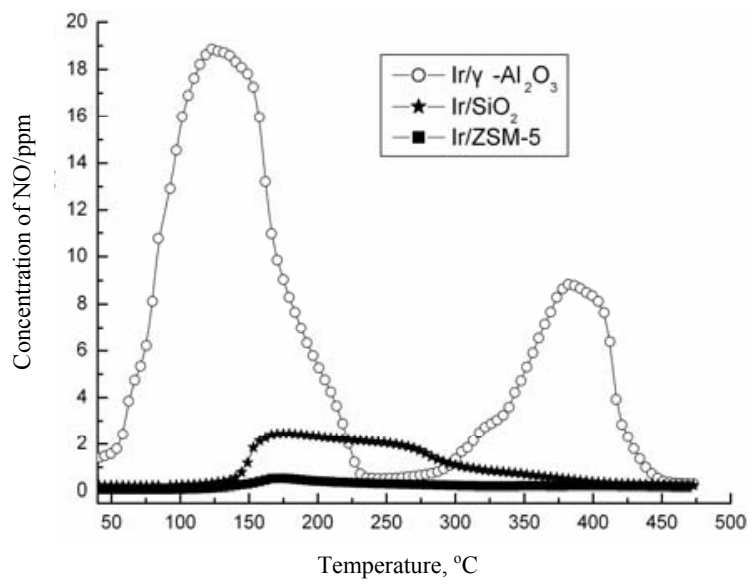

Figure 6. TPD profiles of NO after co-adsorption of $\mathrm{NO}$ and $\mathrm{O}_{2}$ over $\mathrm{Ir} / \mathrm{ZSM}-5, \mathrm{Ir} / \mathrm{SiO}_{2}$ and $\mathrm{Ir} / \gamma-\mathrm{Al}_{2} \mathrm{O}_{3}$ 
The NO oxidation ability with the content of $0.02 \mathrm{wt} . \%$ is in order: $\operatorname{Ir} / \mathrm{ZSM}-5>\operatorname{Ir} / \gamma$ $\mathrm{Al}_{2} \mathrm{O}_{3}>\mathrm{Ir} / \mathrm{SiO}_{2}$, which is similar to that of blank supports. And the activities of NO reduction are weak. These were attributed to the nature of support materials which played an important role when the Ir content was low. The $\mathrm{NO}$ oxidation activity with $0.1 \mathrm{wt} . \%$ and $5 \mathrm{wt} . \%$ is $\mathrm{Ir} / \mathrm{ZSM}-5>\mathrm{Ir} / \mathrm{SiO}_{2}>\mathrm{Ir} / \gamma-\mathrm{Al}_{2} \mathrm{O}_{3}$ and the NO reduction activity is $\mathrm{Ir} / \gamma-\mathrm{Al}_{2} \mathrm{O}_{3}>$ $\mathrm{Ir} / \mathrm{SiO}_{2}>\mathrm{Ir} / \mathrm{ZSM}-5$, which are similar to those of Ir-based catalysts with the content of $1 \mathrm{wt} . \%$.
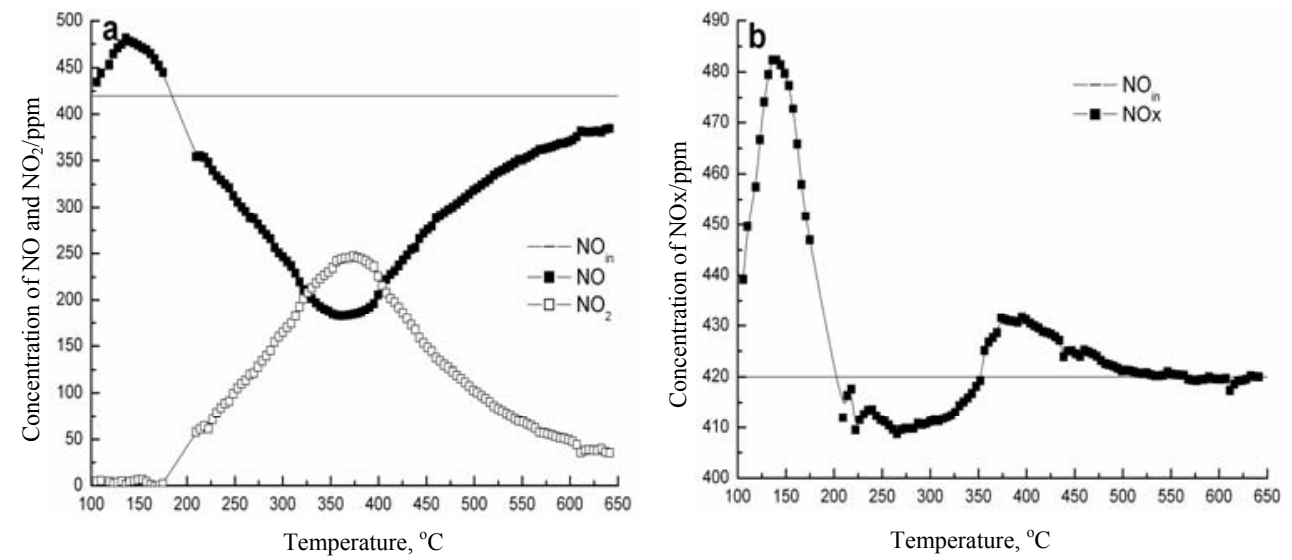

Figure 7. TPR profiles of $\mathrm{NO}, \mathrm{NO}_{2}$ and $\mathrm{NOx}$ over $5 \mathrm{wt} . \% \mathrm{Pt} / \gamma-\mathrm{Al}_{2} \mathrm{O}_{3}$

Comparison between $\mathrm{Ir} / \gamma-\mathrm{Al}_{2} \mathrm{O}_{3}$ and $\mathrm{Pt} / \gamma-\mathrm{Al}_{2} \mathrm{O}_{3}$

Figure 7 shows TPR profiles of $\mathrm{NO}, \mathrm{NO}_{2}$ and $\mathrm{NOx}$ over $5 \% \mathrm{Pt} / \gamma-\mathrm{Al}_{2} \mathrm{O}_{3}$. From the data in Table 2, NO oxidation over $5 \mathrm{wt} . \% \mathrm{Pt} / \gamma-\mathrm{Al}_{2} \mathrm{O}_{3}$ reaches the maximal conversion at $361{ }^{\circ} \mathrm{C}$ and the conversion ratio is $58.8 \%$, which are accordant with $\mathrm{Xue}^{13}$. Compared with $5 \mathrm{wt} . \% \mathrm{Ir} / \gamma$ $\mathrm{Al}_{2} \mathrm{O}_{3}$ in Figure 4 (a), although $\mathrm{NO}$ oxidation activity over $\operatorname{Ir} / \gamma-\mathrm{Al}_{2} \mathrm{O}_{3}$ is lower than that of $\mathrm{Pt} / \gamma-\mathrm{Al}_{2} \mathrm{O}_{3}$ at low temperature, the maximal oxidation conversion is similar to $\mathrm{Pt} / \gamma-\mathrm{Al}_{2} \mathrm{O}_{3}$. Comparing Figure 7 (b) with Figure 4 (b), NO reduction conversion over $\mathrm{Ir} / \gamma-\mathrm{Al}_{2} \mathrm{O}_{3}$ is higher than that over $\mathrm{Pt} / \gamma-\mathrm{Al}_{2} \mathrm{O}_{3}$. Hence, $\mathrm{Ir} / \gamma-\mathrm{Al}_{2} \mathrm{O}_{3}$ is more benificial for $\mathrm{NO}$ reduction than $\mathrm{Pt} / \gamma$ $\mathrm{Al}_{2} \mathrm{O}_{3}$ and this result is accordant with Wang et al. ${ }^{8}$.

\section{Conclusion}

A series of TPR and TPD experiments were carried out in order to give a research on the $\mathrm{NO}$ reactions over Ir-based catalysts in the presence of $\mathrm{O}_{2}$. The oxidation of $\mathrm{NO}$ to $\mathrm{NO}_{2}$ together with the reduction of $\mathrm{NO}_{2}$ to $\mathrm{N}_{2}\left(\right.$ or $\left.\mathrm{N}_{2} \mathrm{O}\right)$ through adsorption and decomposition were observed over Ir-based catalyst and $\mathrm{IrO}_{2}$ is the surface active phase in the NO reactions by XRD analysis. Ir content and support materials both exhibited an effect on the NO reaction over Ir-based catalysts. The activities of the oxidation and reduction of NO increased as Ir loading increased. When the loading less than $0.1 \mathrm{wt} . \%$, NO oxidation activity is $\mathrm{Ir} / \mathrm{ZSM}-5>\operatorname{Ir} / \gamma-\mathrm{Al}_{2} \mathrm{O}_{3}>\mathrm{Ir} / \mathrm{SiO}_{2}$ mainly depended on the nature of support materials. While the loading greater than $0.1 \mathrm{wt} . \%$, the NO oxidation activity is Ir/ZSM-5 $>\mathrm{Ir} / \mathrm{SiO}_{2}>\mathrm{Ir} / \gamma-\mathrm{Al}_{2} \mathrm{O}_{3}$ which was lied on the $\mathrm{Ir}$ dispersion over support materials and the $\mathrm{NO}$ reduction activity is $\mathrm{Ir} / \gamma-\mathrm{Al}_{2} \mathrm{O}_{3}>\mathrm{Ir} / \mathrm{SiO}_{2}>\mathrm{Ir} / \mathrm{ZSM}-5$ which was relied on the adsorbed-dissociation of $\mathrm{NO}_{2}$ over Ir-based catalysts. Compared with Pt catalysts, Ir-based catalyst is more beneficial for NO reduction. 


\section{Acknowledgment}

This work was supported by Natural Scientific Research Innovation Foundation in Harbin Institute of Technology (No.2008), "Double Hundred" Plan of Shenzhen (No.2008) and National Natural Science Foundation of China (No. 20907012).

\section{References}

1. Hirabayashi H, Yahiro H, Mizuno N and Iwamoto M, Chem Lett., 1992, 21, 2235.

2. Yogo K, Tanaka S, Ihara M, Hishiki T and Kikuchi E, Chem Lett., 1992, 21, 1025.

3. Tabata T, Kokitsu M and Okada O, Appl Catal B: Environ., 1995, 6, 225.

4. Ogura M, Hayashi M and Kikuchi E, Catal Today, 1998, 45, 139.

5. Kikuchi E, Takegoshi G, Ishihara T and Matsuda T, 1992 Preprint of 63th Annual Meeting of Chemical Society of Japan, Tokyo, Abstr. No. 3C407.

6. Ogura M, Kawamura A, Matsukata M and Kikuchi E, Chem Lett., 2000, 29, 146.

7. Wang A, Liang D, Xu C, Sun X and Zhang T, Appl Catal B: Environ., 2001, 32(1), 205.

8. Wang A, Ma L, Cong Y, Zhang T and Liang D, Appl Catal B: Environ., 2003, 40, 319-329.

9. Haneda M, Yoshinari T, Sato K, Kintaichia Y and Hamadaa H, Chem Comm., 2003, 2814.

10. Haneda M, Pusparatu, Kintaichi Y, Nakamura I, Sasaki M, Fujitani T and Hamada H, J Catal., 2005, 229, 197.

11. Zhang G, Yamaguchi T, Kawakami H and Suzuki T, Appl Catal B: Environ., 1992, 1, L15.

12. Buchi A, Ohi A and Nakamura M, Appl Catal B: Environ., 1993, 2, 71.

13. Xue E, Seshan K and Ross J R H, Appl Catal B: Environ., 1996, 11(1), 65-79.

14. Amiridis M D, Roberts K L and Pereira C J, Appl Catal B: Environ., 1997, 14(14), 203-209.

15. Blanco J, Odenbrand C U I, Avila P and Knapp C, Catal Today, 1998, 45, 103-108.

16. Iwamoto M, Proc Meet Catal Technol., Tokyo, Jan., 1990, p.17.

17. Shangguan W F, Teraoka Y and Kagawa S, Appl Catal B: Environ., 1997, 12, 237-247.

18. Li Y J and Keith Hall W K, J Catal., 1991, 129, 202. 


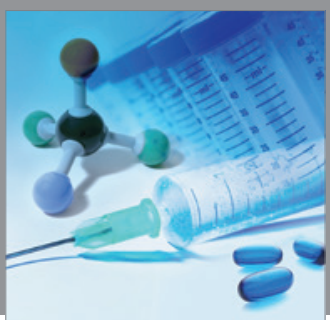

International Journal of

Medicinal Chemistry

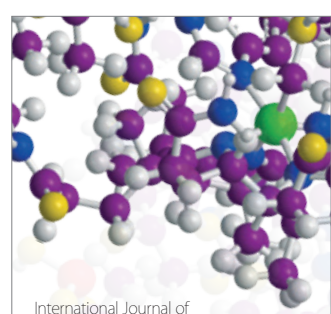

Carbohydrate Chemistry

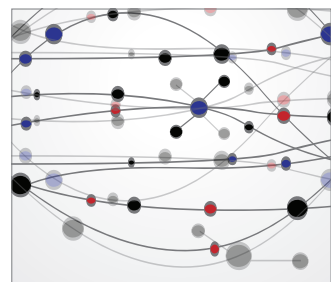

The Scientific World Journal
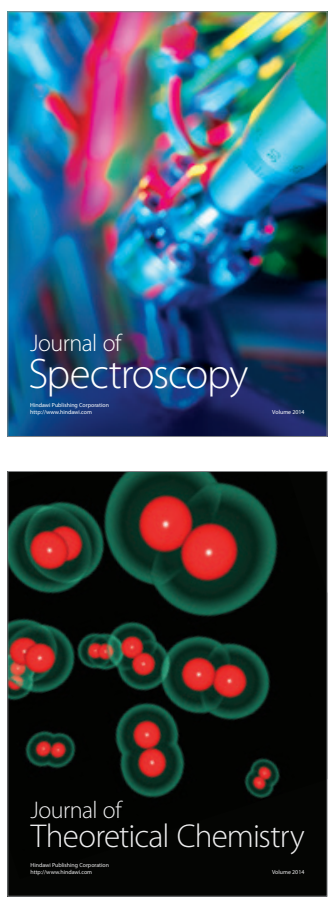
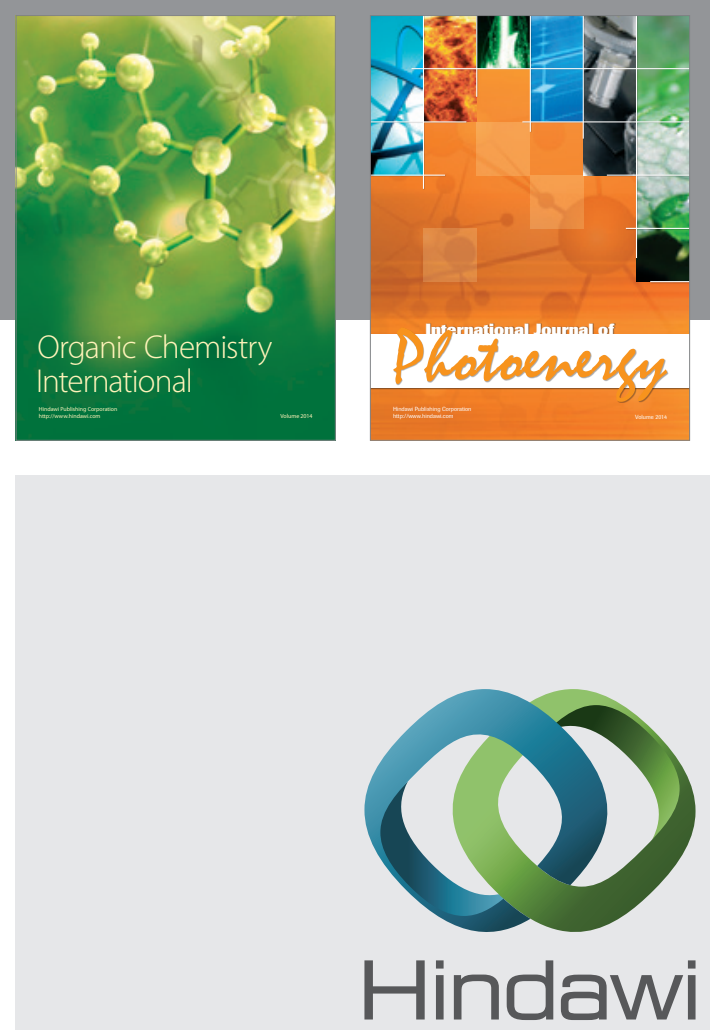

Submit your manuscripts at

http://www.hindawi.com
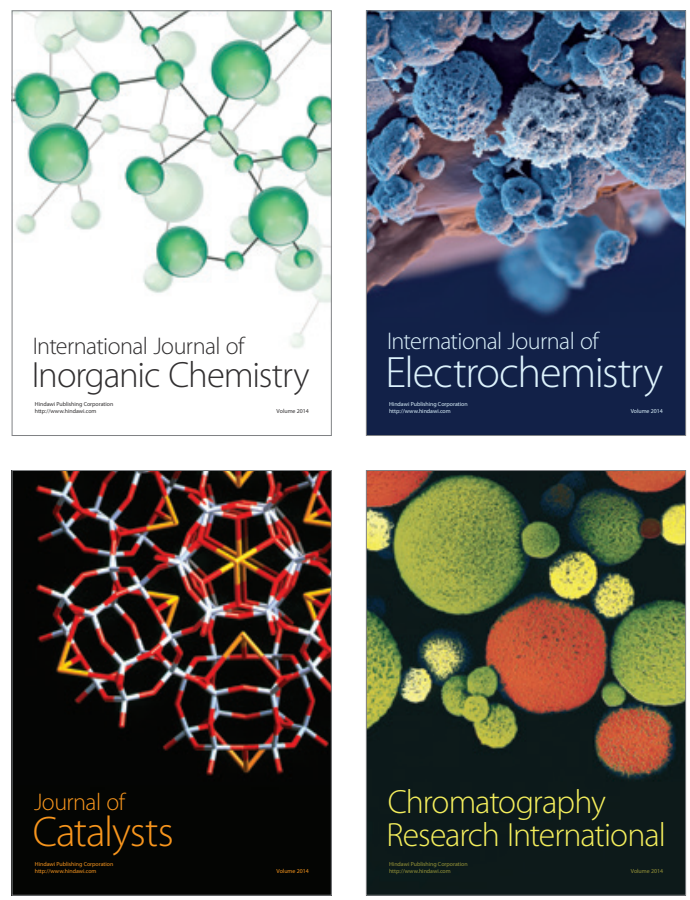
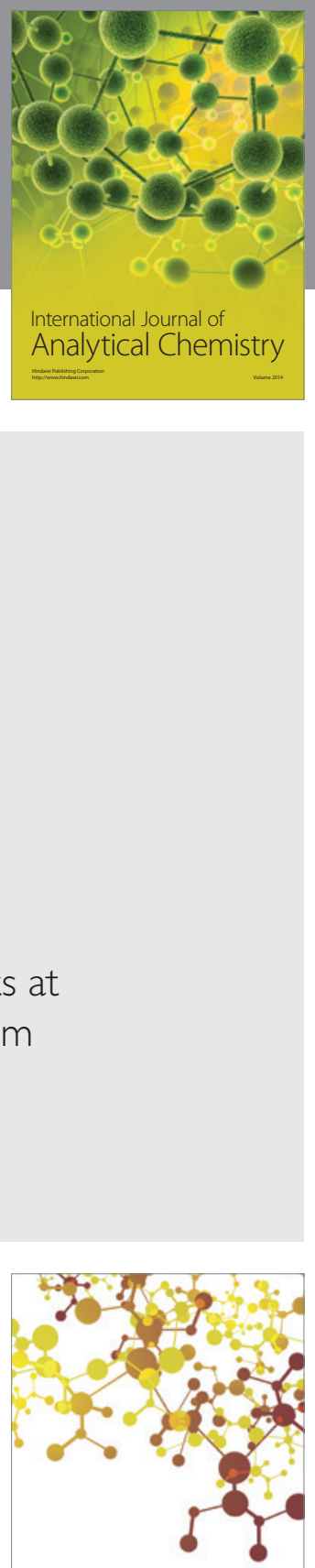

Journal of

Applied Chemistry
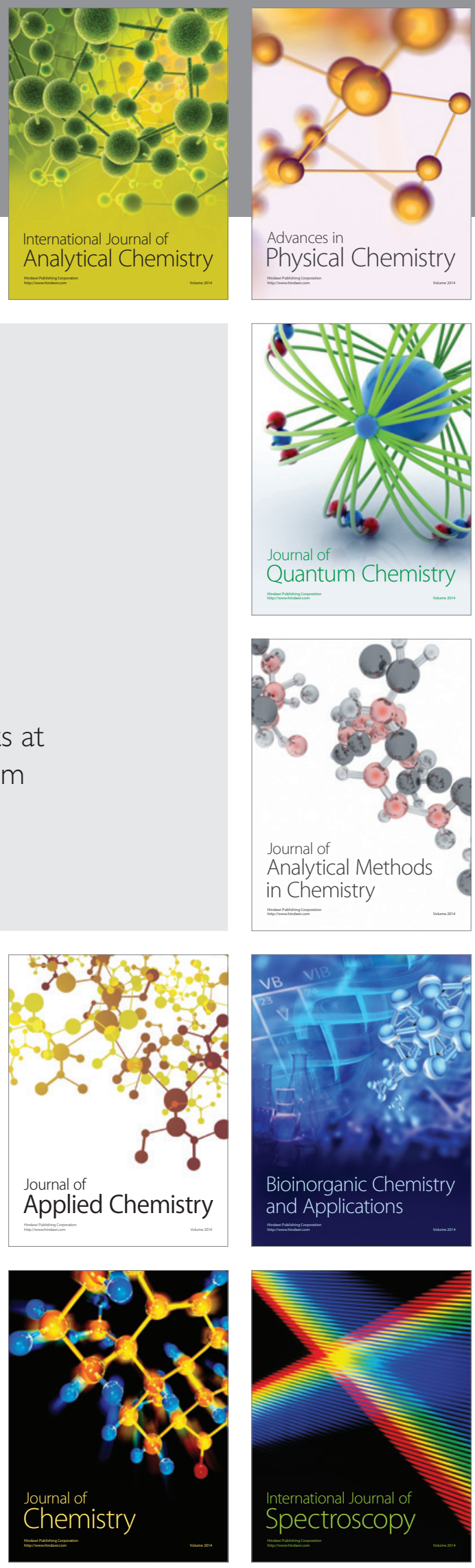